\title{
Temperature Sensor Based on an Asymmetric Two-Hole Fiber Using a Sagnac Interferometer
}

\author{
René Domínguez-Cruz, ${ }^{1}$ Daniel A. May-Arrioja $\left(\mathbb{D},{ }^{2}\right.$ Rodolfo Martínez-Manuel, ${ }^{2}$ \\ and Daniel Lopez-Cortes ${ }^{2}$ \\ ${ }^{1}$ Universidad Autónoma de Tamaulipas, Carretera a San Fernando Cruce con Canal Rodhe, S/N, Col Arcoiris, 88779 Reynosa, \\ TAMPS, Mexico \\ ${ }^{2}$ Centro de Investigaciones en Óptica, Unidad Aguascalientes, Prol. Constitución 607, Fracc. Reserva Loma Bonita, 20200 \\ Aguascalientes, AGS, Mexico
}

Correspondence should be addressed to Daniel A. May-Arrioja; darrioja@cio.mx

Received 19 October 2017; Accepted 19 December 2017; Published 15 February 2018

Academic Editor: Stefania Campopiano

Copyright (c) 2018 René Domínguez-Cruz et al. This is an open access article distributed under the Creative Commons Attribution License, which permits unrestricted use, distribution, and reproduction in any medium, provided the original work is properly cited.

\begin{abstract}
We report in this paper a temperature sensor based on an asymmetric two-hole fiber (ATHF) using a Sagnac interferometer (SI) configuration. The operation principle is based on the birefringence change induced by the temperature difference between the air holes and the silica fiber. As a result, the transmitted spectrum of the SI exhibits a sinusoidal profile which is shifted when the temperature is increased. A linear wavelength shift as a function of temperature is observed, and a sensitivity of $2.22 \mathrm{~nm} /{ }^{\circ} \mathrm{C}$ was achieved using a $2 \mathrm{~m}$ long asymmetric THF, which is in the same order as those previously reported using similar microstructured fibers. The advantage of this system is a linear response, the use of a microstructured fiber with a simpler transverse geometry, and the use of bigger holes which can facilitate the insertion of several materials and improve the sensitivity of the sensor for different applications.
\end{abstract}

\section{Introduction}

Optical metrology based on fiber-optic sensors (FOS) is one of the most promissory technologies due to a wide range of applications. FOS advantages over electronic devices are well known such as lightweight, small size, high sensitivity and operation speed, immunity to electromagnetic interference, resistance to chemical corrosion, remote sensing, and the option of multiplexing optical signals. These suitable features have allowed a variety of studies to apply FOS as sensing indicators for temperature, rotation, strain, pressure, level, refractive index (RI), liquid contamination, and so on [1-3]. The current status, opportunities, and global perspective of FOS are described in [4-7].

In terms of novel optical fibers, the microstructured fiber (MSF) is an attractive component due to its fabrication technology, physical properties, and potential use in several photonic devices. The structure of a MSF is formed by an array of air columns within a silica matrix, which extend along the $z$-axis of the fiber. The size and shape of the holes, their distribution, the insertion of materials into the holes, and the different interferometric arrangements are parameters that allow fabricating of MSF with different structures and geometries. Therefore, this leads to different conditions that optimize the propagation of optical waves along the MSF and enhances its sensing applications [5, 8-14]. In general, there are two configurations that have been mainly used to design MSF sensors: grating and interferometric-based sensors. In the case of grating-based MSF sensors, Bragg gratings (FBGs) [15] and long-period gratings (LPGs) [16] are inscribed along the MSF; meanwhile, for interferometric geometries, different configurations can be used such as the Mach-Zehnder interferometer [17], Sagnac interferometer (SI) [18], Fabry-Pérot interferometer [19], or Michelson interferometer [20]. 
The presence of air holes in MSF and the possibility to be filled with other materials give some important engineering potentials due to improved properties such as high birefringence, large dispersion, and increase in the response to external thermal effects [21]. For instance, temperature measurements have been realized using several types of liquid materials which have been infiltrated into the MSF holes such as isopropanol [22], ethanol [23], refractive index-matching oil [24], alcohol [21], polymers [25], and liquid crystals [26]. In addition, selective filling of the holes is also feasible in order to enhance the sensor sensitivity [27]. A simpler transversal MSF structure, employing a combination of two-side holes which have been filled with indium, has been proposed by Kim et al. [28]. Here, the authors report a sensitivity of $-6.3 \mathrm{~nm} / \mathrm{K}$ in the range of $39-110^{\circ} \mathrm{C}$ using a SI scheme. A similar sensor is reported in [29], where a sensitivity of $-2.58 \mathrm{~nm} /{ }^{\circ} \mathrm{C}$ is obtained using two-side holes inserted in a photonic crystal structure which is filled with water. A temperature sensor based on a two-side-hole fiber has been reported by [30], in which the effect of a crosssectional structure on the birefringence and thermo-optic properties of the side-hole fiber with infiltration of indium metal into the holes are studied by using the SI, where the sensitivity reached is $-11.03 \mathrm{~nm} / \mathrm{K}$ using a $1 \mathrm{~m}$ long fiber. As we mentioned before, the liquid insertion in MSF improves the temperature sensitivity. However, they also have several drawbacks that limit their use such as the cost, preform design, hole-matrix fabrication in the MSF structure, and complex technique in the partial or total filling mechanism $[31,32]$.

In this paper, we report a fiber-optic temperature sensor fabricated with an unfilled segment of an asymmetric twohole fiber (ATHF) in a SI configuration. The operation principle is based on the birefringence changes on the ATHF induced by the temperature difference between the air holes and the silica fiber when the ATHF is heated. In consequence, a spectral shift of the Sagnac interference pattern is observed and used to measure the external temperature. Experimental results exhibit a sensor sensitivity of $2.22 \mathrm{~nm} /{ }^{\circ} \mathrm{C}$, which is on the same order of previously reported schemes. The linear response, the simple fiber transversal structure, and the use of bigger holes that facilitate the insertion of other materials provide an ideal platform for the development of highly sensitive sensors.

\section{Materials and Methods}

2.1. Theoretical Considerations. The SI with birefringent fiber is an attractive and useful component employed for the development of photonic devices in optical communication systems and as a sensor element $[33,34]$. The basic architecture of a SI with birefringent fiber is shown in Figure 1.

The SI is fabricated using a $3 \mathrm{~dB}$ fiber coupler, which splits the input signal in two equal parts. These two output fibers coming from the $3 \mathrm{~dB}$ coupler are spliced with the birefringent fiber to create a closed loop. When a beam is propagated at the input of the fiber coupler, the optical beam is equally divided and propagates in opposite directions in the loop. Later, both signals arrive back to the fiber coupler

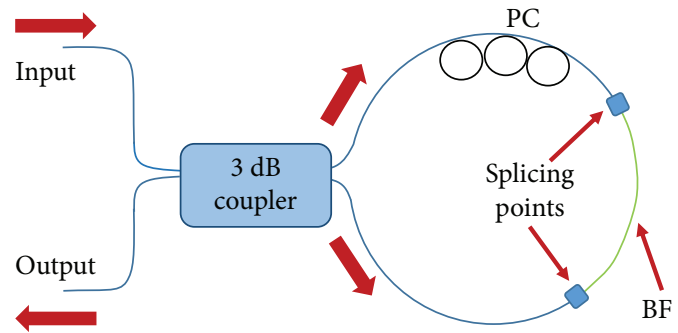

FIgURE 1: Typical configuration of a Sagnac interferometer (SI). PC: polarization controller; BF: birefringent fiber.

output terminals to recombine. The superposition of these beams is well known, and it provides a transmission spectrum with a sinusoidal profile given by [34]

$$
T=\left[\sin \frac{\beta L}{\lambda} \cos \left(\theta_{1}+\theta_{2}\right)\right]^{2},
$$

where $L$ is the length of the birefringent fiber, $\lambda$ is the wavelength of the input beam, and $\theta_{1}$ and $\theta_{2}$ are the angles between the light at both ends of the birefringent fiber with respect to the fast or slow axis of the fiber, respectively. The birefringence $\beta$, defined by the difference in refractive indexes along the fast axis $\left(n_{y}\right)$ and the slow axis $\left(n_{x}\right)$, can also be related in terms of the wavelength spacing spectrum $(\Delta \lambda)$ as follows [35]:

$$
\Delta \lambda=\frac{\lambda^{2}}{\beta L} .
$$

From (2), we can notice that changes in wavelength spacing or spectral shift will be observed when the birefringence is modified by an external perturbation such as temperature.

2.2. Experimental Description. The temperature measurements were carried out using the experimental setup shown in Figure 2. The system consists of a Thorlabs superluminescent laser diode (JDSU emitting from 1450 to $1630 \mathrm{~nm}$ and centered in $1545 \mathrm{~nm}$ ) which is used as the input optical signal into the interferometer. The SLD was operated using current and temperature controllers, Thorlabs LDC220C and TED200C, respectively, in order to avoid intensity fluctuations from the optical source. The SI was fabricated with a $3 \mathrm{~dB}$ splitter connected to the ATHF segment (length $L=2 \mathrm{~m}$ ) by fusion splicing. The ATHF was manufactured at Acreo Fiberlab (Kista, Sweden). A standard electric arc fusion splicer was used for this purpose (Fujikura model $70 S$ ). Into the loop, a manual polarization controller (PC) is incorporated (Thorlabs, LC-900) in order to control the polarization propagating into the loop. The transmitted spectrum from the SI was measured with an optical spectrum analyzer, OSA (Anritsu, MS9740A). The ATHF segment was placed into an ultrasonic bath filled with water (Branson, model $3800 \mathrm{CPXH}$ ) which includes a temperature controller with a temperature resolution of $1^{\circ} \mathrm{C}$.

The cross section of the ATHF used as the sensing element is shown on the right side of Figure 2. The diameters of the cladding are $125 \mu \mathrm{m}$ and $5.6 \mu \mathrm{m}$ for the core. Two holes 


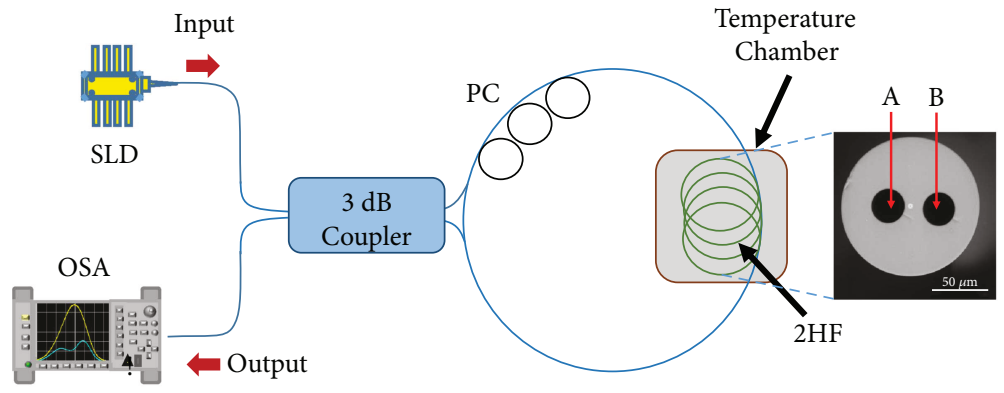

Figure 2: Experimental setup to test the ATHF as a temperature sensor. Right side, a cross section of the ATHF.

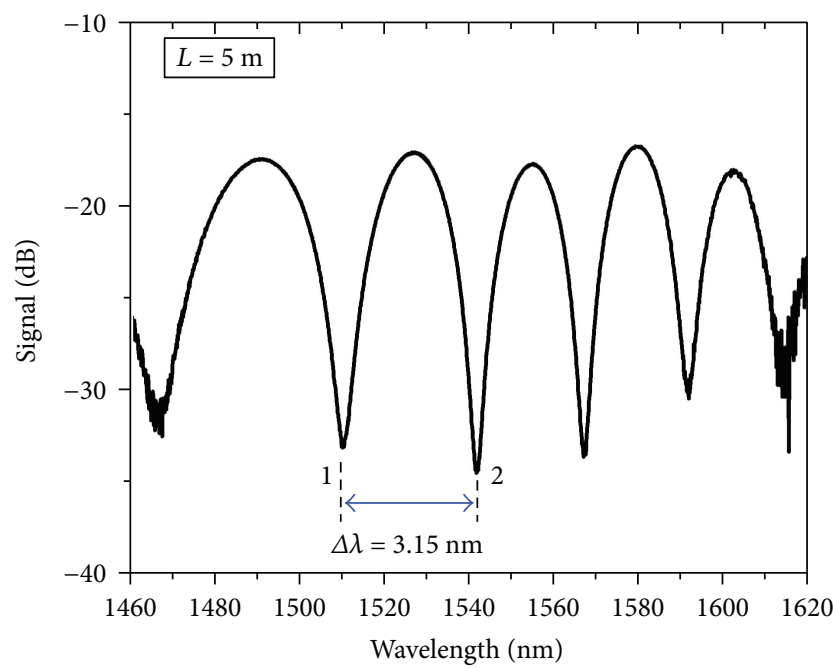

(a)

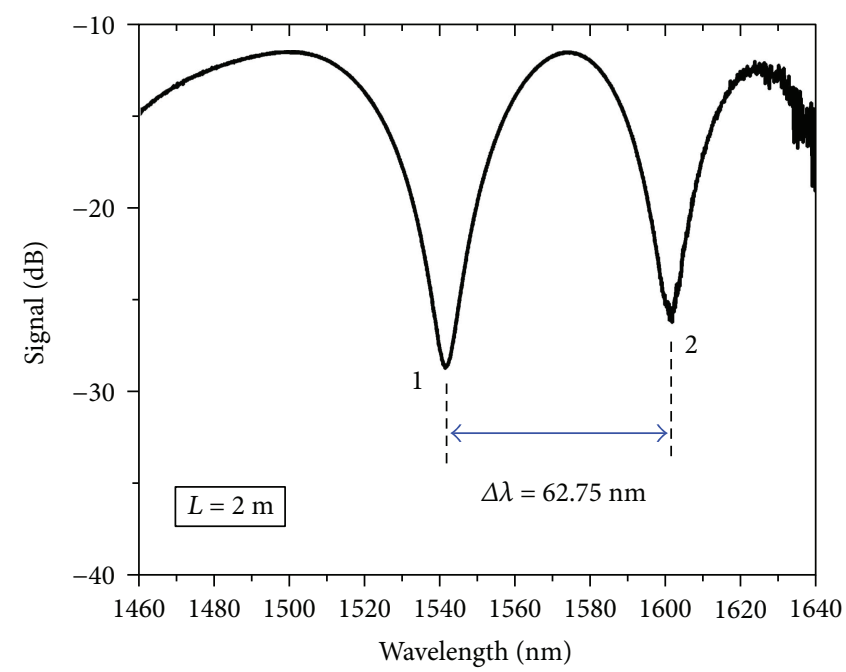

(b)

FIgURE 3: Transmission spectra of the SI fabricated with the ATHF for the (a) $5 \mathrm{~m}$ length and the (b) $2 \mathrm{~m}$ length at room temperature.

(with diameters $A=29 \mu \mathrm{m}, B=27 \mu \mathrm{m}$ ) are asymmetrically located into the fiber: the center of hole $A$ is located at $27 \mu \mathrm{m}$ from the center of the fiber core while the center of hole B is located $20 \mu \mathrm{m}$ away from the center of the fiber core. We should highlight that the hole diameters are larger to facilitate the insertion of other materials. Nevertheless, the splicing to standard single-mode fibers (SMF) was performed using standard splicing procedures. When a broadband source is used to interrogate the ATHF, a sinusoidal response is obtained on the transmitted spectrum. In Figure 3, we present the SI spectra for two different ATHF lengths at room temperature.

In Figure 3(a), we observe the characteristic transmission spectra of a SI for $L=5 \mathrm{~m}$. In this case, the separation obtained between dip 1 and dip 2 provides a fringe separation of approximately $\Delta \lambda=31.5 \mathrm{~nm}$. Under these conditions and using (2), the birefringence is estimated to be $\beta=1.3127 \times$ $10^{-5}$. For experiments where a single dip will be monitored, we selected an ATHF with a shorter length $(L=2 \mathrm{~m})$ into the SI, which increased the separation between consecutive dips as shown in Figure 3(b). In this case, the estimated birefringence obtained by using (2) was reduced to a value of $\beta=7.9546 \times 10^{-6}$. We believe that such small birefringence difference can be related with small variations of the transverse position of the holes along the ATHF. With these conditions, we proceed to perform the characterization of the interferometric system with respect to temperature.

\section{Results and Discussion}

Once the fiber length for the SI was defined, we placed the ATHF inside a thermal bath. This system allows controlled temperature increments with small intervals of $\Delta T=2^{\circ} \mathrm{C}$ from the room temperature $\left(20^{\circ} \mathrm{C}\right)$. Figure $4(\mathrm{a})$ shows the transmitted spectrum of the SI, corresponding to a temperature increment from $20^{\circ} \mathrm{C}$ to $40^{\circ} \mathrm{C}$, with temperature intervals of $4^{\circ} \mathrm{C}$. At each temperature increment, we acquire the respective transmission spectra by using an OSA.

From the transmission spectra at room temperature, we select a dip situated in a $1546.12 \mathrm{~nm}$, black line in Figure 4(a), as the initial reference position. When the temperature is increased, the position of the dip is shifted to longer wavelengths. This is due to the temperature difference between the air holes and the rest of the silica fiber when the ATHF is heated in the water bath. In consequence, birefringence is also changed and the transmitted spectrum is also modified, which can be monitored by following the spectral shift of the selected dip. The wavelength shift as a function of the applied temperature is shown in Figure 4(b), and a good linear approximation can be considered. Under 


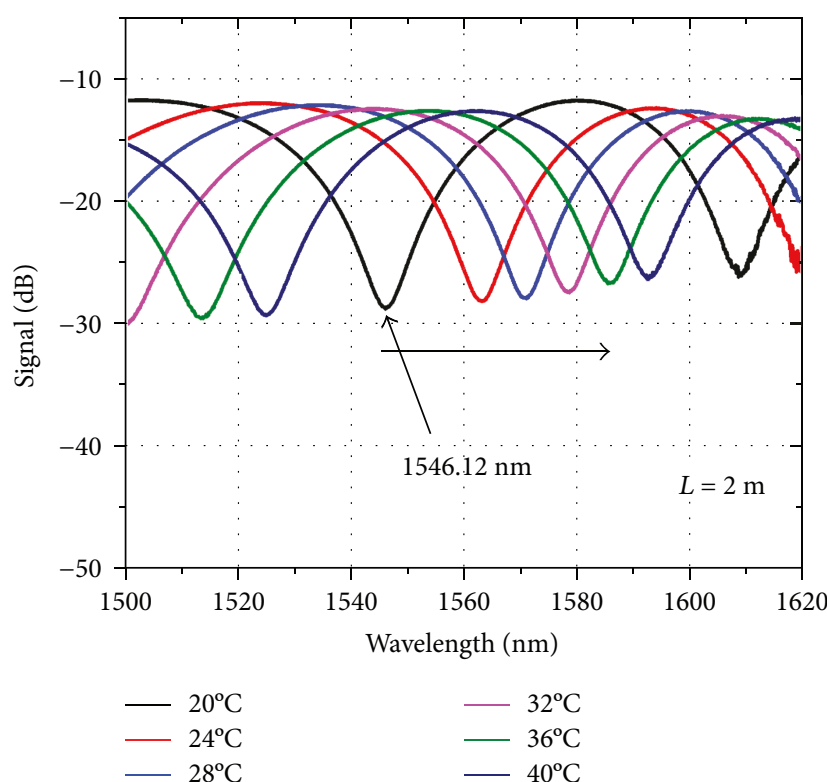

(a)

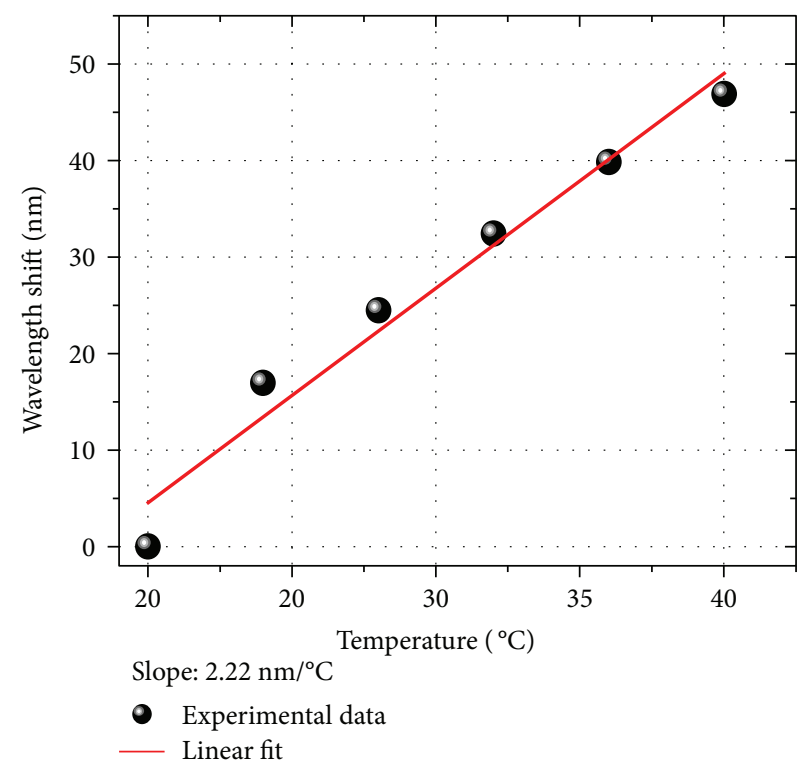

(b)

Figure 4: (a) Transmission spectra of the SI at different temperatures and (b) experimental wavelength shift as a function of temperature and its linear fitting.

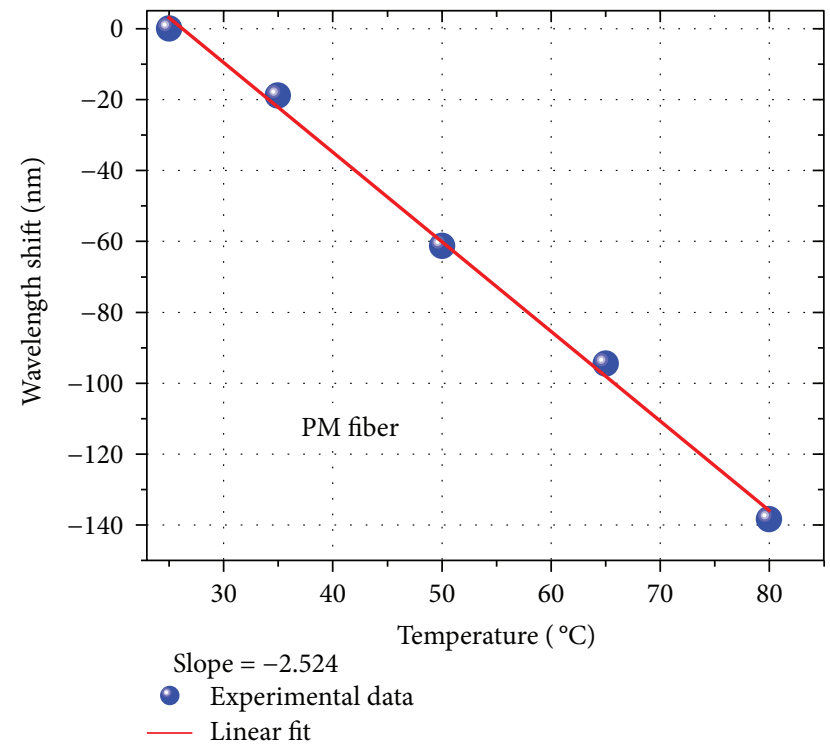

FIgURE 5: Wavelength shift as a function of temperature for a commercial polarization maintaining fiber (PMF).

this linear model, a slope close to $2.22 \mathrm{~nm} /{ }^{\circ} \mathrm{C}$ is obtained in a range from 20 to $40^{\circ} \mathrm{C}$.

For comparison purposes, we performed similar experiments using a commercial polarization-maintaining fiber (PMF) using the same interferometric configuration. In this case, we replace the ATHF in the SI setup with a segment of PMF (Thorlabs, model PM1550-HP, operating wavelength $1440-1625 \mathrm{~nm}$ ) with a length $L=10 \mathrm{~cm}$. This length of fiber produces a similar transmission spectrum as the ATHF, a pair of dips in the wavelength range of the study, as shown in Figure 3(b). By monitoring the wavelength shift of the dip as a function of temperature, we can obtain the sensitivity of the commercial PMF. As shown in Figure 5, the wavelength shift as a function of temperature also exhibits a linear response and can be easily approached to a linear fitting, which provides a slope of $-2.54 \mathrm{~nm} /{ }^{\circ} \mathrm{C}$. This value is of similar order to the one obtained for the ATHF. However, we consider that the ATHF fiber has an advantage because it offers the possibility of increasing the thermal sensitivity if the holes are filled with a suitable thermo-optic material. In Table 1, different techniques using MSF filled with different materials are summarized. We can observe that by properly filling the holes of the MSF, it is possible to increase the sensitivity of the MSF sensor. In addition, our ATHF has bigger holes which can facilitate the insertion of several materials and improve the sensitivity of the sensor for different applications.

\section{Conclusions}

A fiber-optic sensor based on an ATHF was demonstrated using a SI configuration, and the optical characteristics of the sensor were experimentally investigated. The wavelength response as a function of the applied temperature exhibits a linear response with a sensor sensitivity of around $2.22 \mathrm{~nm} /{ }^{\circ} \mathrm{C}$. Although this value is of similar order to the ones previously obtained with similar MSF structures, we believe that the proposed ATHF fiber has an advantage because it offers the possibility of increasing the thermal sensitivity if the holes are filled with a suitable thermo-optic material. In this respect, the ATHF has bigger holes as compared to similar two-hole fiber configurations, which can facilitate the insertion of several materials and improve the sensitivity of the sensor for different applications. 
TABLE 1: Comparison of recent temperature sensors using different birefringent fibers.

\begin{tabular}{|c|c|c|c|c|}
\hline & Technique & $\begin{array}{l}\text { Sensitivity } \\
\left(\mathrm{nm} /{ }^{\circ} \mathrm{C}\right)\end{array}$ & $\begin{array}{l}\text { Operation } \\
\text { range }\left({ }^{\circ} \mathrm{C}\right)\end{array}$ & $\begin{array}{l}\text { Length } \\
(\mathrm{cm})\end{array}$ \\
\hline \multicolumn{5}{|c|}{ Filled fibers } \\
\hline [22] & $\begin{array}{l}\text { Liquid-sealed photonic crystal fiber (PCF) in-line nonpolarimetric } \\
\text { modal interferometer }\end{array}$ & -0.166 & $23.7-66.1$ & 1.15 \\
\hline [23] & Ethanol-filled PCF combined with a fully collapsed splicing with single-mode fibers & -0.35 & $20.0-50.0$ & 3.25 \\
\hline [24] & Fully liquid-filled PCF Mach-Zehnder interferometer & -1.83 & $23.2-58.2$ & 7.5 \\
\hline [29] & $\begin{array}{l}\text { Selectively filled polarization-maintaining PCF (PM-PCF) in a } \\
\text { Sagnac interferometer configuration }\end{array}$ & 2.58 & $25.0-42.0$ & 11.7 \\
\hline \multirow{2}{*}{ [21] } & \multirow{2}{*}{ Alcohol-filled PCF loop mirror } & 6.6 & $8.0-20.0$ & \multirow{2}{*}{6.1} \\
\hline & & 6.2 & $20.0-34.0$ & \\
\hline \multirow{3}{*}{ [8] } & SLI based on a side-hole PCF filled with metal & & & \multirow{3}{*}{20} \\
\hline & In-filled & -9.0 & $22.4-46$ & \\
\hline & Bi-filled & -1.80 & $21.6-70.7$ & \\
\hline \multicolumn{5}{|c|}{ Unfilled fibers } \\
\hline [36] & PANDA fiber in a SL configuration & -1.46 & $40-60$ & 6 \\
\hline [34] & Bow-tie fiber in a SL configuration & -1.23 & $45-75$ & 0.356 \\
\hline This work & $\begin{array}{l}\text { ATHF using a } S L \text {, based on the birefringence change induced by } \\
\text { the temperature difference between the air holes and the silica fiber }\end{array}$ & 2.2 & $20.0-40.0$ & 200 \\
\hline In this work & PM fiber in a SL configuration & -2.54 & $20.0-80.0$ & 10 \\
\hline
\end{tabular}

\section{Conflicts of Interest}

The authors declare no conflicts of interest.

\section{Acknowledgments}

René Domínguez-Cruz and Daniel Lopez-Cortes thank CONACYT for the sabbatical and postdoctoral fellowship assigned, respectively, to carry out this work. The ATHF used in this work was fabricated at Acreo Fiberlab.

\section{References}

[1] B. H. Lee, Y. H. Kim, K. S. Park et al., "Interferometric fiber optic sensors," Sensors, vol. 12, no. 12, pp. 2467-2486, 2012.

[2] S. Silva, P. Roriz, and O. Frazão, "Refractive index measurement of liquids based on microstructured optical fibers," Photonics, vol. 1, no. 4, pp. 516-529, 2014

[3] M. R. Islam, M. M. Ali, M. H. Lai, K. S. Lim, and H. Ahmad, "Chronology of Fabry-Perot interferometer fiber-optic sensors and their applications: a review," Sensors, vol. 14, no. 4, pp. 7451-7488, 2014.

[4] B. Culshaw, "Fibre optic sensor technology - an engineering reality or a scientific opportunity?," Proceedings of SPIE, vol. 7653, article 765304, 2010.

[5] M. A. Schmidt, A. Argyros, and F. Sorin, "Hybrid optical fibers - an innovative platform for in-fiber photonic devices," Advanced Optical Materials, vol. 4, no. 1, pp. 13-36, 2016.

[6] A. Ricciardi, A. Crescitelli, P. Vaiano et al., "Lab-on-fiber technology: a new vision for chemical and biological sensing," Analyst, vol. 140, no. 24, pp. 8068-8079, 2015.

[7] X. Qiao, Z. Shao, W. Bao, and Q. Rong, "Fiber Bragg grating sensors for the oil industry," Sensors, vol. 17, no. 3, 2017.

[8] E. Reyes-Vera, C. M. B. Cordeiro, and P. Torres, "Highly sensitive temperature sensor using a Sagnac loop interferometer based on a side-hole photonic crystal fiber filled with metal," Applied Optics, vol. 56, no. 2, pp. 156-162, 2017.

[9] E. Reyes-Vera and P. Torres, "Influence of filler metal on birefringent optical properties of photonic crystal fiber with integrated electrodes," Journal of Optics, vol. 18, no. 8, article 085804, 2016.

[10] J. H. Osório, J. G. Hayashi, Y. A. V. Espinel, M. A. R. Franco, M. V. Andrés, and C. M. B. Cordeiro, "Photonic-crystal fiber-based pressure sensor for dual environment monitoring," Applied Optics, vol. 53, no. 17, pp. 3668-3672, 2014.

[11] G. Hu and D. Chen, "Side-hole dual-core photonic crystal fiber for hydrostatic pressure sensing," Journal of Lightwave Technology, vol. 30, no. 14, pp. 2382-2387, 2012.

[12] G. Chesini, C. M. B. Cordeiro, C. J. S. de Matos, M. Fokine, I. C. S. Carvalho, and J. C. Knight, "All-fiber devices based on photonic crystal fibers with integrated electrodes," Optics Express, vol. 17, no. 3, pp. 1660-1665, 2009.

[13] E. Reyes-Vera, N. D. Gómez-Cardona, G. Chesini, C. M. B. Cordeiro, and P. Torres, "Temperature sensibility of the birefringence properties in side-hole photonic crystal fiber filled with indium," Applied Physics Letters, vol. 105, no. 20, article 201101, 2014.

[14] C. Wu, J. Li, X. Feng, B.-O. Guan, and H.-Y. Tam, "Side-hole photonic crystal fiber with ultrahigh polarimetric pressure sensitivity," Journal of Lightwave Technology, vol. 29, no. 7, pp. 943-948, 2011.

[15] A. Cusano, D. Paladino, and A. Iadicicco, "Microstructured fiber Bragg gratings," Journal of Lightwave Technology, vol. 27, no. 11, pp. 1663-1697, 2009.

[16] G. Humbert, A. Malki, S. Février, P. Roy, and D. Pagnoux, "Characterizations at high temperatures of long-period gratings written in germanium-free air-silica microstructure fiber," Optics Letters, vol. 29, no. 1, pp. 38-40, 2004.

[17] B. Kim, T.-H. Kim, L. Cui, and Y. Chung, "Twin core photonic crystal fiber for in-line Mach-Zehnder interferometric sensing 
applications," Optics Express, vol. 17, no. 18, pp. 15502-15507, 2009.

[18] Z. Liu, C. Wu, M. L. Tse, and H. Y. Tam, "Fabrication, characterization, and sensing applications of a high-birefringence suspended-core fiber," Journal of Lightwave Technology, vol. 32, no. 11, pp. 2113-2122, 2014.

[19] C. Wu, Z. Liu, a. P. Zhang, B.-O. Guan, and H.-Y. Tam, "In-line open-cavity Fabry-Pérot interferometer formed by C-shaped fiber for temperature-insensitive refractive index sensing," Optics Express, vol. 22, no. 18, pp. 21757-21766, 2014.

[20] A. Zhou, Y. Zhang, G. Li et al., "Optical refractometer based on an asymmetrical twin-core fiber Michelson interferometer," Optics Letters, vol. 36, no. 16, pp. 3221-3223, 2011.

[21] W. W. Qian, C. L. Zhao, S. L. He et al., "High-sensitivity temperature sensor based on an alcohol-filled photonic crystal fiber loop mirror," Optics Letters, vol. 36, no. 9, pp. 15481550, 2011.

[22] S. J. Qiu, Y. Chen, F. Xu, and Y. Q. Lu, “Temperature sensor based on an isopropanol-sealed photonic crystal fiber in-line interferometer with enhanced refractive index sensitivity," Optics Letters, vol. 37, no. 5, pp. 863-865, 2012.

[23] W. Qian, C. L. Zhao, C. C. Chan et al., “Temperature sensing based on ethanol-filled photonic crystal fiber modal interferometer," IEEE Sensors Journal, vol. 12, no. 8, pp. 2593-2597, 2012.

[24] Y. Geng, X. Li, X. Tan, Y. Deng, and X. Hong, "Compact and ultrasensitive temperature sensor with a fully liquidfilled photonic crystal fiber Mach-Zehnder interferometer," IEEE Sensors Journal, vol. 14, no. 1, pp. 167-170, 2014.

[25] Y. Huang, Y. Xu, and A. Yariv, "Fabrication of functional microstructured optical fibers through a selective-filling technique," Applied Physics Letters, vol. 85, no. 22, pp. 51825184, 2004.

[26] T. T. Larsen, A. Bjarklev, D. S. Hermann, and J. Broeng, "Optical devices based on liquid crystal photonic bandgap fibres," Optics Express, vol. 11, no. 20, pp. 2589-2596, 2003.

[27] T. Han, Y. Liu, Z. Wang et al., "Unique characteristics of a selective-filling photonic crystal fiber Sagnac interferometer and its application as high sensitivity sensor," Optics Express, vol. 21, no. 1, pp. 122-128, 2013.

[28] B. H. Kim, S. H. Lee, A. Lin, C. Lee, J. Lee, and W. Han, "Large temperature sensitivity of Sagnac loop interferometer based on the birefringent holey fiber filled with metal indium," Optics Express, vol. 17, no. 3, pp. 1789-1794, 2009.

[29] Y. Cui, P. P. Shum, D. J. J. Hu, G. Wang, G. Humbert, and $\mathrm{X}$. Dinh, "Temperature sensor by using selectively filled photonic crystal fiber Sagnac interferometer," IEEE Photonic Journal, vol. 5, no. 5, 2012.

[30] S. H. Lee, B. H. Kim, D. H. Son, S. Jeong, Y. Kim, and W.-T. Han, "Effect of cross-sectional structure on optical properties of metal filled side-hole fiber," Journal of Lightwave Technology, vol. 33, p. 1, 2015.

[31] J. A. Ju, H. F. Xuan, W. Jin, S. J. Liu, and H. L. Ho, "Selective opening of airholes in photonic crystal fiber," Optics Letters, vol. 35, no. 23, pp. 3886-3888, 2010.

[32] R. Spittel, D. Hoh, S. Brückner et al., "Selective filling of metals into photonic crystal fibers," Photonic and Phononic Properties of Engineered Nanostructures, vol. 7946, article 79460Z, 2011.

[33] D. B. Mortimore, "Fiber loop reflectors," Journal of Lightwave Technology, vol. 6, no. 7, pp. 1217-1224, 1988.
[34] O. Frazão, J. M. Baptista, and J. L. Santos, "Recent advances in high-birefringence fiber loop mirror sensors," Sensors, vol. 7, no. 11, pp. 2970-2983, 2007.

[35] J. Noda, K. Okamoto, and Y. Sasaki, "Polarization-maintaining fibers and their applications," Journal of Lightwave Technology, vol. 4, no. 8, pp. 1071-1089, 1986.

[36] J. Zhang, X. Qiao, T. Guo et al., "Highly sensitive temperature sensor using PANDA fiber Sagnac interferometer," Journal of Lightwave Technology, vol. 29, no. 24, pp. 3640-3644, 2011. 


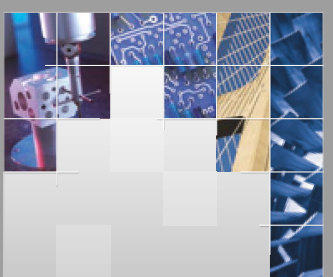

\section{Enfincering}
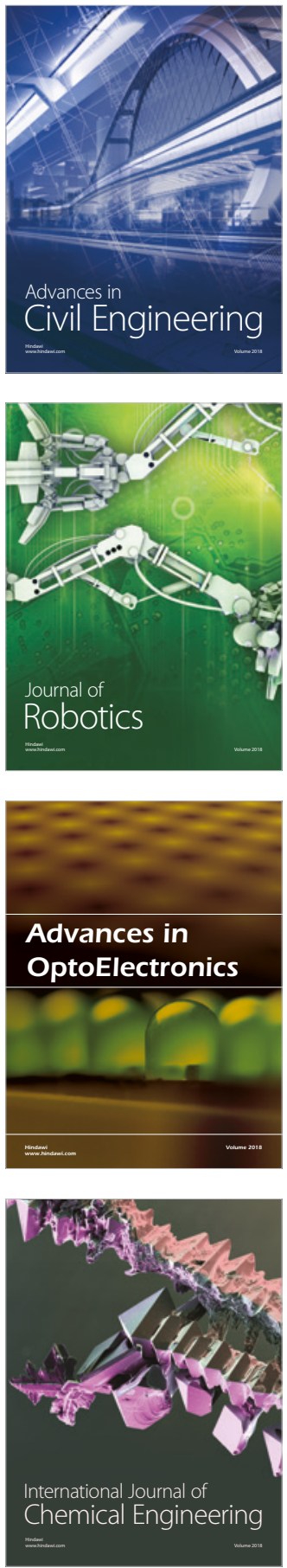

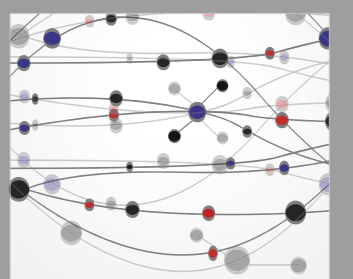

\section{Rotating \\ Machinery}

The Scientific World Journal

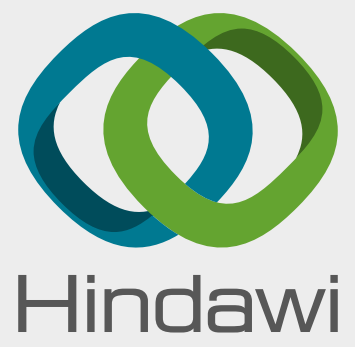

Submit your manuscripts at

www.hindawi.com
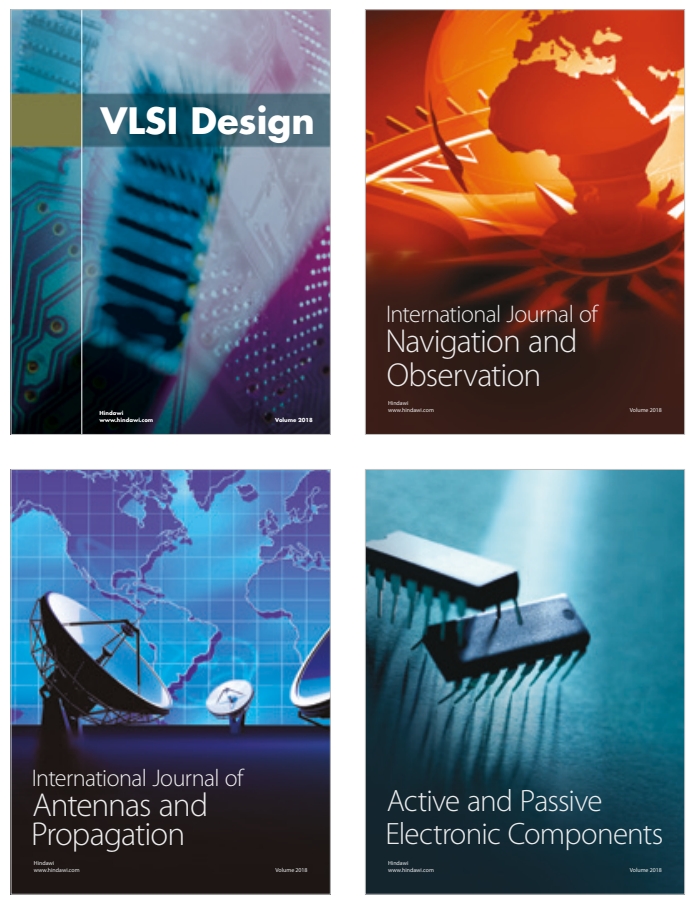
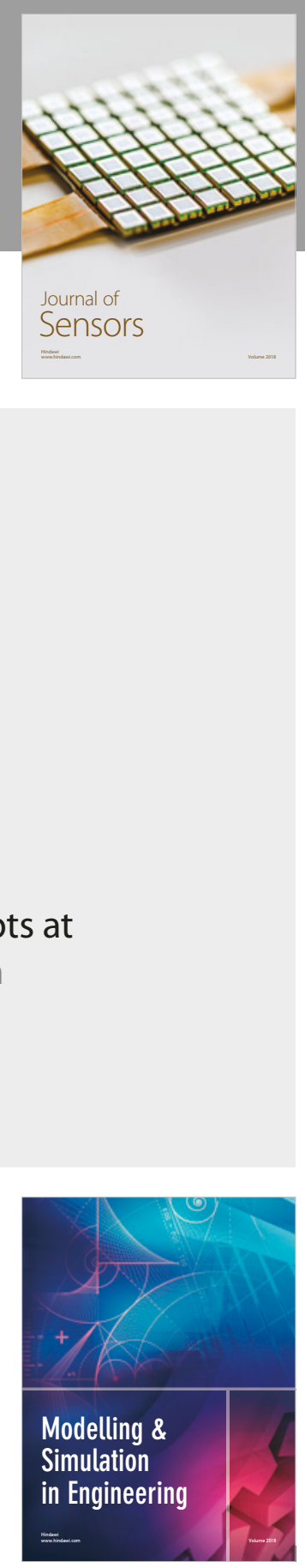

\section{Advances \\ Multimedia}
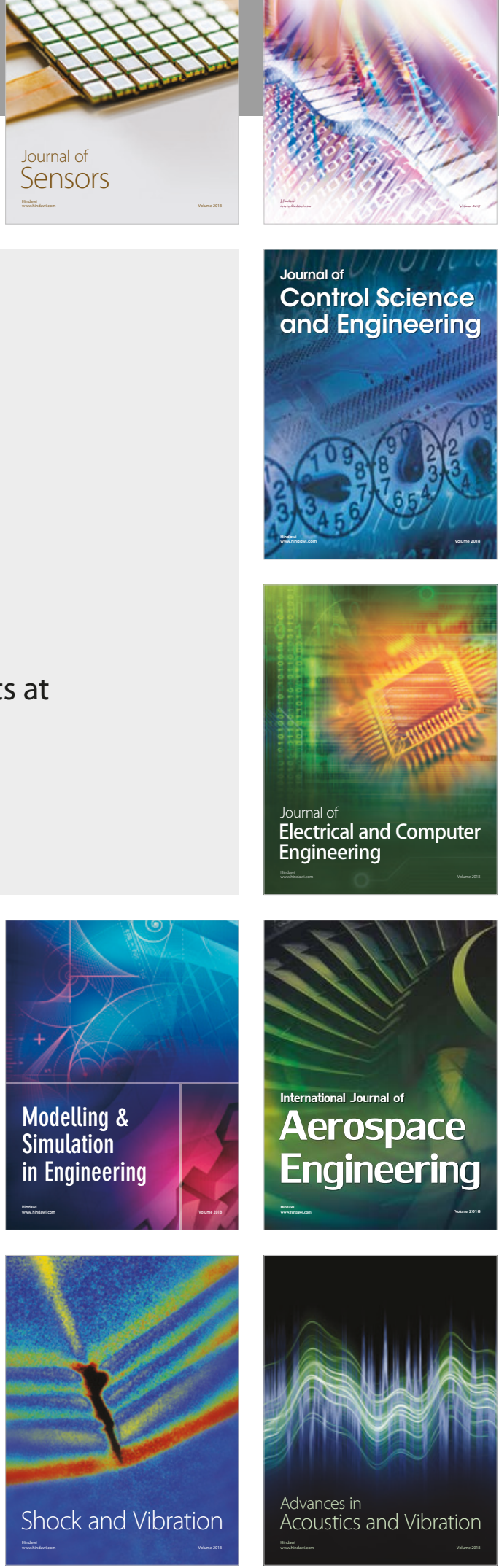